\title{
Editorial
}

\section{False aneurysm of the left ventricle}

In this issue four cases are described ${ }^{1-4}$ in which the authors illustrate their experience with the very uncommon surgical challenge of false (or pseudo) aneurysm of the left ventricle. Although this condition is seen infrequently, it should be recognised and distinguished from the common type of left ventricular aneurysm. It is said to have a propensity for rupture, and may cause symptoms of heart failure. It is eminently operable if it is approached with an understanding of its anatomy and certain characteristic features.

The basis of the condition is a contained rupture of the free wall of the myocardium..$^{5-8}$ Acute rupture of the myocardium is in fact quite common. Of patients dying of infarction, $17 \%$ have been found to have ruptured the heart through the infarcted area. ${ }^{9}$ Free wall rupture is four to five times more common than septal rupture, ${ }^{9}$ presumably a simple reflection of the relative volumes of myocardium at risk, but it is usually immediately fatal. These are among the cases described as "EDM" (electromechanical dissociation) when they collapse some days after infarction, with a peak incidence at 3-5 days. ${ }^{7}$ The ventricle is beating but no output is generated because of tamponade. The patients with ruptured myocardium who survive to operation in the period soon after infarction, we see as the familiar acute septal rupture, loosely known as "infarct VSD". The UK Cardiac Surgical Register (of the Society of Cardiothoracic Surgeons of Great Britain and Ireland) records about 200 operations each year for this condition, with a mortality of $35-40 \%$. This has changed very little over the past 20 years. Ruptured papillary muscle is also a familiar surgical condition.

The early descriptions of false aneurysm of the ventricle are dominated by pathological descriptions from Jesse Edwards's department. ${ }^{6-8}$ The cases were identified postmortem and included patients dying of late rupture of the false aneurysm. As a surgeon, the few cases that I see are the survivors who come to operation with the aneurysm intact. What is the true natural history and how many will rupture if not treated? The cases in the literature are so sporadic, documented in ones ${ }^{10-17}$ and $\operatorname{twos}^{818}$ or small series $^{19-24}$ that I am very uncertain of the characteristic natural history. Without more data of the true denominator, all that can be said is that rupture is a risk ${ }^{6-8} 14{ }^{25}{ }^{26}$ but its true frequency is unknown. In life, false aneurysm is most often a finding in the course of investigation of a patient with ischaemic heart disease. It has been described following mitral valve replacement, presumably as a late presentation of posterior wall rupture. ${ }^{27} \mathrm{~A}$ false aneurysm may be picked up by echocardiography, or on left ventricular angiography. Occasionally they are so large that the plain chest $x$ ray shows a dramatic bulge. Once suspected, echocardiography is probably the most practical way of assessing the anatomy and monitoring change in size ${ }^{128}$ while magnetic resonance imaging gives unequalled anatomical information. ${ }^{2}$

In pathological terms a typical ventricular aneurysm can be regarded as a "true" aneurysm in the sense that the sac contains the three layers of the vessel wall, the endocardium and epicardium sandwiching a layer of thinned fibrous tissue that is the remnant of the left ventricular muscle. The wall of a false aneurysm consists of adherent pericardium and associated postinflammatory scar tissue, with some remnants of the epicardium. The key for the clinician is to be able to distinguish, in life, false aneurysm from the familiar left ventricular aneurysm. In contrast to the typical postinfarction aneurysm, which is in wide open continuity with the cavity of the left ventricle, the false aneurysm has a well defined neck, which is the rent in the infarct, through which the aneurysm arose. Typically this is relatively narrow and consists of stout scar tissue, in marked contrast with the tapering poorly defined zone of continuity between ventricular muscle and the usual left ventricular aneurysm. Repair is thus easy, both because the suture line is easily defined and the tissues lend themselves to secure surgical repair.

The indications for operation are debatable, and in such a rare entity each case must be considered on its merits. If surgery for coronary artery disease is indicated on the usual grounds, repair of such a defect in the wall of the ventricle is easily undertaken at the time. If there are manifestations of left ventricular dysfunction we get into the difficult discussion of whether the symptoms are likely to be alleviated by resection of the aneurysm. The phase image of a MUGA scan seems to me to be the best way to make the decision if it is difficult. However, if a substantial proportion of the left ventricular work is involved in filling and tensing a large but useless sac, its exclusion is likely to be of benefit. That has been my experience, albeit in a very small series of cases. Finally, should we consider whether repair is indicated purely to preempt rupture. That is the received wisdom in the text books. ${ }^{25}{ }^{26}$ The argument would at least make weight in favour of surgery if an operative decision is in the balance. It is also a compelling reason for operating on an incidentally discovered aneurysm in a patient being operated on for angina. There may be a case for regular monitoring and using change in size as an indication, but there are no data available to guide us.

A final word about surgical technique - the mistake is to think in terms of dissecting out, mobilising, and then resecting the aneurysm. The word "resection" is best excluded from the operative discussion at the outset, because it indicates a dangerous and inappropriate approach to this pathological entity. The surgeon should establish bypass, gain control, prevent ejection by cardioplegia or left ventricular fibrillation, and then enter the sac. ${ }^{16} 2025$ This both reduces the risk of disastrous bleeding and avoids systemic embolism. ${ }^{17}$ The neck must be defined but with no more than essential dissection. Direct suture is usually easy and, unless there has been an error in diagnosis or technique, there should be no need for foreign material such as pledgets, or the use of a patch. Any clot or debris can be tidied up, but the thin sac of pericardium can simply stay where it is.

1 Hung M-J, Wang C-H, Cherng W-J. Unruptured left ventricular pseudoan-

2 Chakraborty RN, Nicholson AA, Alamgir MF. Magnetic resonance images of left ventricular pseudoaneurysm. Heart 1998;80:101-3. 
3 Reinecke H, Wichter T, Weyand M. Left ventricular pseudoaneurysm in a patient with Dressler's syndrome after myocardial infarction. Heart patient with D

4 Togni M, Hilfiker P, Follath F. Ruptured ventricular pseudoaneurysm. Heart 1998;80:97.

5 Roberts WC, Morrow AG. Pseudoaneurysm of the left ventricle. An unusual sequel of myocardial infarction and rupture of the heart. $\mathrm{Am} \mathcal{F} \mathrm{Med}$ 1967;43:639-44.

6 Chesler E, Korns ME, Semba T, et al. False aneurysm of the left ventricle following myocardial infarction. Am f Cardiol 1969;23:76-82.

7 Van Tassel RA, Edwards JE. Rupture of the heart complicating myocardial infarction. Analysis of 40 cases including nine examples of left ventricular false aneurysm. Chest 1972;61:104-18.

8 Zlodaver Z, Coe JI, Edwards J. True and false ventricular aneurysms: propensity for the latter to rupture. Circulation 1975;51:567-73.

9 Dellborg M, Held P, Swedberg K, et al. Rupture of the myocardium. Occurrence and risk factors. Br Heart f 1985;54:11-16.

10 Hurst CO, Gerald F, Keyes JW. Pseudoaneurysm of the heart: report of a case and review of the literature. Circulation 1963;28:427-35.

11 McIlmoyle G, McLoughlin MJ, Silver MD. Massive false aneurysm of the left ventricle with dysphagia. Can Med Assoc F 1973;109:388-91.

12 Harper RW, Sloman G, Westlake G. Successful surgical resection of a chronic false aneurysm of the left ventricle. Chest 1975;67:359-61.

13 Woo KS, Agnew TM, Graham KJ. Cardiac rupture with false aneurysm after myocardial infarction. $N Z$ Med f 1976;83:230-2.

14 Allen JW, Madge GE. False aneurysm of the left ventricle following myocardial infarction: case report. Mil Med 1977;142:75-6.

15 Martin RH, Almond CH, Saab S, et al. True and false aneurysms of the left ventricle following myocardial infarction. Am f Med 1977;62:418-24.

16 Landymore R. Surgical management of left ventricular pseudoaneurysms. Can F Surg 1982;25:670-1.

17 Coupe M, Dancy M, Pepper J. Coincidence of true and false left ventricular aneurysms after myocardial infarction. Br Heart $\mathcal{7}$ 1986;56:567-8.

18 Yakierevitch V, Vidne B, Melamed R, et al. False aneurysm of the left ventricle: surgical treatment. F Thorac Cardiovasc Surg 1978;76:556-8.
19 Rittenhouse EA, Sauvage LR, Mansfield PB, et al. False aneurysm of the left ventricle: report of four cases and review of the surgical literature. Ann Surg 1979;189:409-15.

20 Stewart S, Huddle R, Stuard I, et al. False aneurysm and pseudo-false aneurysm of the left ventricle: etiology, pathology, diagnosis, and operative management. Ann Thorac Surg 1980;31:259-64.

21 Catherwood E, Mintz GS, Kotler MN, et al. Two-dimensional echocardiographic recognition of left ventricular pseudoaneurysm. Circulation 1980;62:294-303.

22 Shabbo FP, Dymond DS, Rees GM, et al. Surgical treatment of false aneurysm of the left ventricle after myocardial infarction. Thorax 1983;38:2530.

23 Komeda M, David TE. Surgical treatment of postinfarction false aneurysm of the left ventricle. F Thorac Cardiovasc Surg 1993;106:1189-91.

24 Mackenzie JW, Lemole GM. Pseudoaneurysm of the left ventricle. Texas Heart Inst f 1994;21:296-301.

25 Kirklin JW, Barratt-Boyes BG. Cardiac surgery. New York: John Wiley \& Sons, 1986:296.

26 White HD. Myocardial infarction. In: Julian DG, Camm AJ, Fox KM, et al, eds. Diseases of the heart. London: Saunders, 1996:1055.

27 Sakai K, Nakamura K, Ishizuka N, et al. Echocardiographic findings and clinical features of left ventricular pseudoaneurysms after mitral valve replacement. Am Heart f 1992;124:975-81.

28 Lascault G, Reeves F, Drobinski G. Evidence of the inaccuracy of standard echocardiographic criteria used for the recognition of true and "false" left ventricular aneurysms. Br Heart f 1988;60:125-7.

TOM TREASURE

Cardiothoracic Unit,

St George's Hospital,

London SW17 0QT, UK 